\title{
Questes
}

\section{Violences médiévales : conclusion}

\section{Léonard Dauphant}

\section{(2) OpenEdition \\ Journals}

\section{Édition électronique}

URL : http://journals.openedition.org/questes/451

DOI : 10.4000/questes.451

ISSN : 2109-9472

\section{Éditeur}

Les Amis de Questes

\section{Édition imprimée}

Date de publication : 15 mars 2008

Pagination : 99-101

ISSN : 2102-7188

\section{Référence électronique}

Léonard Dauphant, «Violences médiévales : conclusion », Questes [En ligne], 14 | 2008, mis en ligne le 01 janvier 2014, consulté le 15 septembre 2020. URL : http://journals.openedition.org/questes/451 


\section{Conclusion}

\section{Léonard DAUPHANT}

«Violence médiévale »: la première séance de cette année questeuse abordait un thème à la fois vaste et central, parce que les sources n'en sont jamais exemptes, qu'il sert de plus en plus de fil conducteur aux études sociales et historiques de la période. Il ne pouvait s'agir ici de faire une synthèse prématurée, mais d'explorer ou rouvrir quelques pistes. Devant l'ampleur du programme et la hausse considérable des études dont la violence est l'objet, les communications ont eu le triple intérêt de mêler retours sur de vénérables dossiers (le Perlesvaus, la bataille de Visby, la prophétie politique) et interrogations transversales ou pluri-disciplinaires (faisant par exemple le lien entre iconographie et archéologie, ou entre histoire des représentations et des idées politiques), et enfin de tenter de passer de la brutalité du fait particulier à l'approche de la réalité générale de la violence médiévale, sans se contenter de généralités ni d'anecdotes.

La violence est d'abord ${ }^{1}$ objet de représentation, d'une surprenante plasticité. Motif littéraire, interrogeant le goût et la sensibilité du temps quant à sa représentation, il s'agit d'abord de la violence insoutenable du Perlesvaus dont Patrick Moran reprend pour nous l'étude. Son écriture paroxystique renvoie-t-elle en définitive à une violence de la Fin des Temps, horizon du monde médiéval, où la modération n'a plus de sens, tout comme la notion de violence, qui y est contenue en creux? L'exemple de Guiron présenté par Sophie Albert illustre au contraire le traitement paradoxal d'une violence «enchantée », dont la réalité cruelle est

\footnotetext{
${ }^{1}$ «D'abord » pour le chercheur, qui a accès en premier lieu aux sources écrites.
} 
volontairement masquée pour être retournée en une coutume légitime exotique. Ces deux exemples vont d'un extrême à l'autre du traitement littéraire de la violence, qui se révèle barbarie: d'un côté, la violence absolue, sans entraves et presque sans rémission, devenue pourtant légitime, de l'autre la négation de sa réalité au profit du renversement d'une marge lointaine où le chevalier se révèle naïvement barbare.

La représentation n'est évidemment pas neutre et peut être orientée dans un but didactique, moral ou politique. Le discours sur la violence vise à déterminer l'action brutale qui relève de l'humain et celle qui aboutit à l'inutile cruauté. La communication de Jean-Baptiste Delzant, qui explore les différentes visions que les chroniques italiennes donnent d'une vendetta dans l'Ombrie du Quattrocento, offre à la fois le témoignage de la réception régionale d'un fait divers particulièrement meurtrier, et un bon exemple de la manipulation politique de la violence, présentée comme moyen de gouvernement par Sercambi. Le compte rendu de l'ouvrage de Barbara Morel présente quant à lui l'image d'une justice dont la représentation figurée édulcore la rigueur: indice d'une illégitimité de la répression, qui, pour apparaître plus nécessaire que cruelle, doit masquer sa réalité? Les représentations de la violence apparaissent d'une variété extrême selon le contexte, entre l'apologie qu'en fait un théoricien politique italien et la négation par le milieu judiciaire français. Dans ces exemples pratiques, la fin semble justifier les moyens, qu'ils soient démonstration ou dissimulation de force.

La violence est aussi et surtout la violence vécue directement. On peut évoquer, au niveau le plus commun et le plus bénin, la violence de l'injure, dont Vanessa Obry présente l'étude par Dominique Lagorgette. On pense également à la violence sociale du châtiment du crime, objet du compte rendu de Nicole Gonthier par Pierre Levron : la violence apparaît plus que jamais sous un double visage à la fin du Moyen Âge, quand l'augustinisme politique érige la répression en gardienne de la société mais aussi en éducatrice des déviants. Il s'agit enfin, bien entendu, de la 
violence guerrière. On ne s'étonnera guère que les $\mathrm{XIV}^{\mathrm{e}}$ et $\mathrm{XV}^{\mathrm{e}}$ siècle aient fourni l'essentiel des communications. La guerre se présente sous les deux aspects de la bataille rangée et de la guerre de courses et de pillages. D'un côté comme de l'autre, pour aller au-delà des épisodes bien connus par les chroniques ou aborder le quotidien des guerriers et des victimes civiles, l'historien doit affronter le problème du manque de sources. Renaud Figueres reprend le dossier archéologique de la bataille ou plutôt du massacre de Visby, exemple d'un affrontement inégal, qui tourne à la déroute. Les données sont exceptionnelles, mais d'une grande complexité de traitement. C'est au contraire une anecdote, presque un non-événement dont nous parle Bruno Varennes. Car qu'est-ce qu'un raid de routier dans le sud de la France au $\mathrm{XIV}^{\mathrm{e}}$ siècle? Une incursion à nos yeux inattendue, dans une région qui aurait dû être épargnée, et d'une dramatique banalité pendant la Guerre de Cent Ans. Cette violence ordinaire ou endémique, qui se passe de discours comme de justifications, est pourtant fondamentale à prendre en compte, bien qu'elle reste invisible dans son omniprésence. Il faut recourir à de brèves mentions postérieures pour la débusquer et en cerner les contours, dans une véritable archéologie du texte cette fois.

L'utilisation de la violence apparaît ainsi objet de manipulation par excellence, donnant lieu à une essentielle duplicité : selon le cas, le discours blâme l'excès ou loue la vertu de force. Le rejet de la violence se place ainsi au centre de l'arsenal idéologique pour déterminer et distinguer la légitimité d'une cause, au risque de la déshumanisation non seulement de la victime mais aussi de l'agresseur. Les mêmes actes vus sous l'angle concret de leur déroulement, dégagés de leur enveloppe discursive, deviennent infiniment plus fuyants. Au-delà de sa manipulation, la recherche de la réalité invisible de la violence médiévale semble offrir encore de nombreuses perspectives, aussi bien devant l'évidence des textes littéraires que dans la confusion des vestiges matériels encore inexplorés. 